SMITH: Will that cause any problems in use?

NELLIST: I don't think so. People may need to become accustomed to the idea, but internal areas can work very well. And no one will be working there all the time. They will come for an hour or so, half a day, or perhaps a day at most.

SMITH: Given what you said before, about the rather odd proportions of the Great Hall, do you think that the end result - with a still very tall room for the library-might actually be an improvement?

NELLIST: It would be presumptuous of me to say that it will be an improvement. It will be something very different from what is there at the moment, though, of course, retaining Lutyens's detail and, I hope, in keeping with what Lutyens might have done in other circumstances.

\title{
Minerva unmasked
}

\section{R S MORTON}

From time to time colleagues have unsuccessfully sought to learn the identity of our regular contributor, Minerva. I am now in a position to reveal all. The accompanying photograph is of an early sighting but it should help members of the British Medical Association to recognise her at a glance. She was named in Rome and clearly carries her years admirably.

The likeness is by the late Renaissance Dutch artist, Otto van Veen (1556-1629). He executed it in 1595 after spending some years in Italy, where he interested himself in the history and literature of Greece and Rome. Two titles have been given to the work, "Image of Indiscreet Youth" and "Allegory on the Temptation of Youth." Devotees of Minerva assure me that she is not personalised in the first title, nor is she the temptress suggested in the second.

The youth referred to is male and we find him central, reclining

on a pillow, the classical symbol of la dolce vita. An old Dutch proverb, doubtlessly known to van Veen, says, "Idleness is the pillow of the Devil." The work is a good example of mannerism, and all the other characters are figures from classical mythology. Centre left is Bacchus, with a smile and an inviting gesture as he holds out some grapes. Behind him is his wine bloated, pug nosed, stepfather, Selenius; behind him is Ceres, Goddess of the Harvest. The figure in the left foreground has a muscularly male right arm tugging at the youth's clothing, but the figure's profile, headgear, and apparel suggest a woman. Could the figure be Liberia, a regular companion of Bacchus? This seems more likely than it be some anonymous bacchante, wantonly devoid of her customary fillet of ivy. Perhaps Minerva can remember who was at the party?

Centrally is Venus with her chariot drawn by doves. See how she

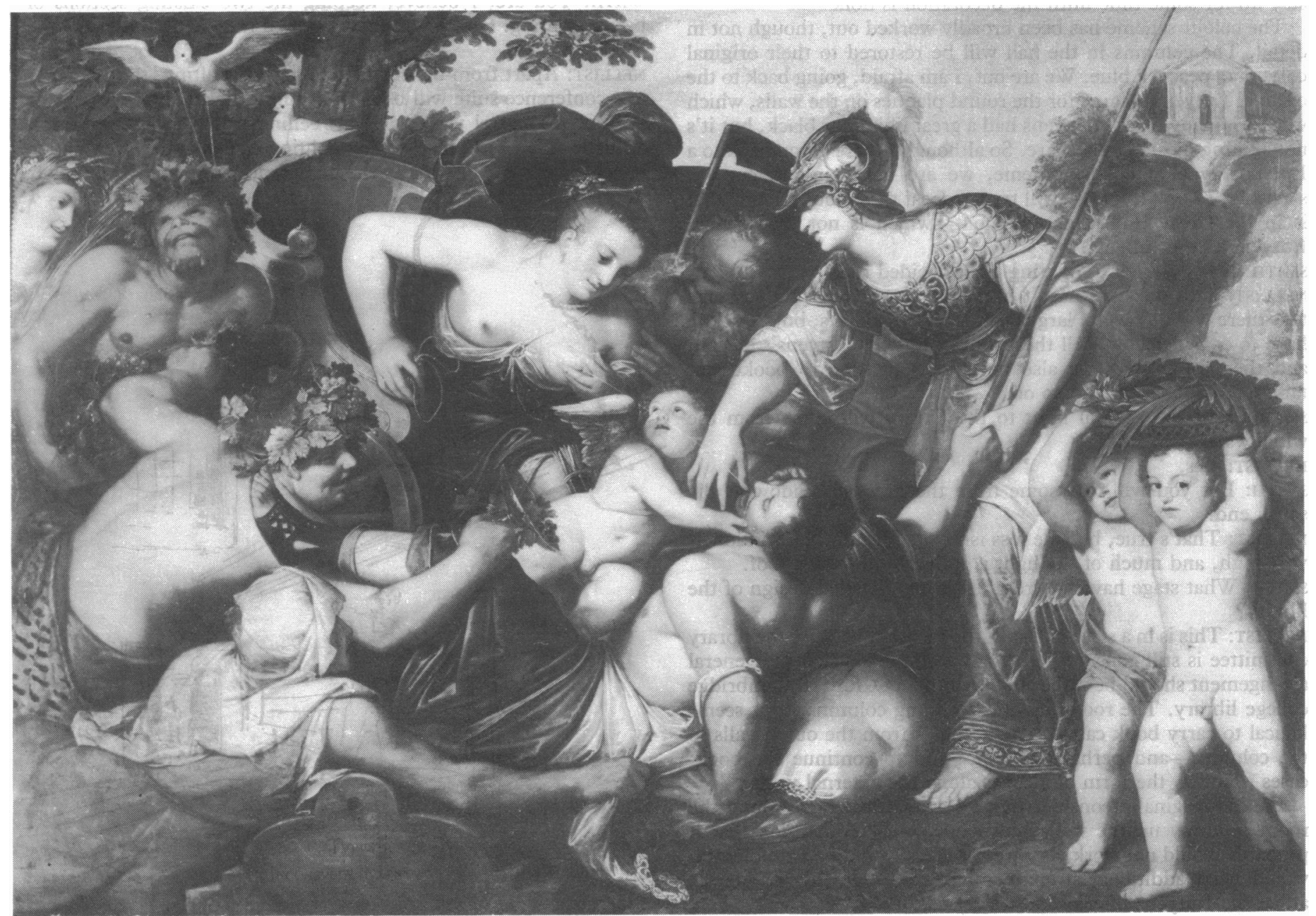

National Museum Stockholm Copyright. 
holds the reins. In her shadow is Chronus with a restraining hand on her left shoulder. The milk motif in association with Venus signifies serious contamination in classical paintings. Cupid shows interest and the two putti or cherubs in the right foreground share a wreath of laurels, symbol of virginity.

And there is Minerva. Is she not resplendent in her everyday wear of plumed helmet, long spear, and breast plate fronted by the Gorgon Medusa's head, with hair replaced by serpents? Note how fittingly these serpents intertwine to suggest BMA membership. She is dressed just as she was when she is said to have leapt from Jupiter's brain, mature, on the day of her birth. And what of her looks? Was not Milton in his Comus right to describe her as of "noble grace"? Little wonder she thought herself fit to compete with Juno and Venus for Paris's golden apple.

What is a nice girl like Minerva doing in such mixed company? Her past history is helpful. As a Roman goddess she identifies both with the Greek goddess Athena and a counterpart in earlier Minoan mythology. In this last, she was protectress of palaces, and we find

The University, Sheffield

R S MORTON, MBE, MD, honorary lecturer history of medicine

Correspondence to: 9 Cortworth Road, Sheffield S11 9LN. two of these in the top right hand corner of our picture. In Greece and Rome she presided over the workers in useful and ornamental arts and trades. She was Goddess of Memory and, incidentally, a warlike divinity, so it is not surprising that the painting, currently in the National Museum in Stockholm, was booty of war in 1648 . Minerva has another attribute. Did she not deservedly earn a reputation for wisdom the day she competed with Neptune for the possession of Athens? The city was to be awarded to the one who produced the gift most useful to mortals. Neptune produced the horse; Minerva chose the olive.

Something more of Minerva is revealed in the picture. She is trying to protect the youth by a gesture aimed at deflecting the symbolically contaminating stream of milk as he rises to temptation. With her left hand Minerva restrains him. Her practical compassion, alas, proves unavailing.

What do the painting, and the titles accorded it, really mean? What indiscretion is imaged? What insight does Minerva share with van Veen in the title "Allegory of the Temptation of Youth?"

Seventy years were to elapse before, in 1664, the truth became apparent. Can you hazard a guess as to what it was? More importantly, can Minerva remember what it was? Or is her reputed association with impeccable memory to remain part of her past myth and present mystery?

The answer will be found on page 1772 .

\section{Fly fisher's finger}

I want to report a new sign associated with fly fishing. At the height of the fly fishing season last year'a patient in his 40s developed severe pain and swelling in his left middle finger. The finger was particularly painful and swollen the morning after a full day's boat fishing on Rutland Water. The proximal interphalangeal joint was red, swollen, and had limited movement. Within 48 hours this had settled with no specific treatment other than rest. It occurred on two further occasions after similar expeditions.

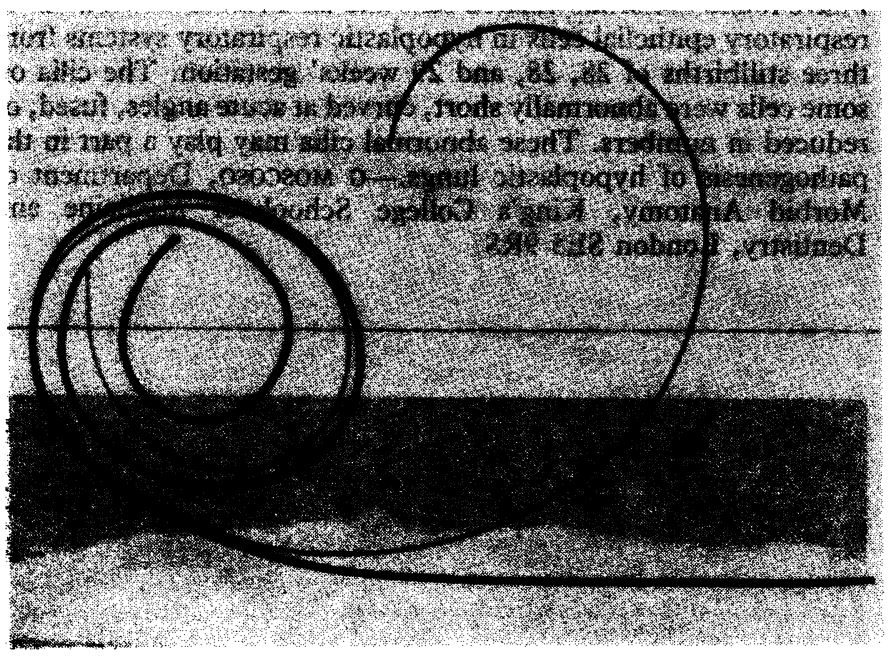

Over the past few years there has been a dramatic change in fly fishing techniques, particularly on large reservoirs. The traditional lightweight tackle approach of catching surface fish has been replaced in many instances by fishermen adopting deep sea trawler like tactics. This entails using heavily loaded lines which sink rapidly to the bottom, where monster trout may lie waiting. Indeed, trout of $10 \mathrm{lb}$ or more are often caught at Rutland Water. Many metres of line lie out behind the boat, which is moving with the wind on the rudder. This line is then rapidly retrieved, usually by the left hand in a right-handed person, and trauma results to the fingers.

This technique has many rewards for the aficionados of this style but is abhorred by the traditionalists. It is likely to increase, particularly as more specimen trout are being caught in the deeper waters.-A C B WICKS, physician, Leicester.

\section{Cooperation between government and coal miners}

The coal mining dispute reminds me of an incident during the second world war when the government was eager to secure the maximum cooperation of coal miners.

In 1940, E A Aslett and I were engaged in the Medical Research Council studies of chronic pulmonary disease in South Wales coal miners. Our headquarters were in Ammanford (Dyfed). At one point it was decided to investigate the possible relation of tuberculous infection to pneumoconiosis by assessing the tuberculin skin sensitivity of Ammanford colliery workers showing different chest radiographic appearances. Cooperation in our main investigation (composed of clinical examination, radiography, and a detailed history of underground experience) had been excellent and freely given; but the proposed intracutaneous injections were considered an extra imposition, and, after consultation with the lodge committee, a payment of half a crown was agreed for each participant.

An initial test, with 1 tuberculin unit was given. A proportion, of course, proved negative to this weak dose, and we proposed to give a second test of 100 units to these "negatives." We had assumed that the initial payment would cover the second test too; but there were rumblings among those requiring it. A crisis was on us since the second test (in our scheme) had to be done no later than 48 hours after the first.

John (now Sir John) McMichael, who was with us temporarily to make some physiological assessments, stepped into the breach. At a hastily called lodge meeting he made an eloquent speech (worthy of an election candidate) dealing with medical progress, miners' welfare, etc, and won the men over-provided that a second half crown would be given. A second crisis-no money. So I telephoned the MRC in London, and a bag full of half crowns arrived by train in the nick of time, allowing the tests to be completed. Incidentally, the survey showed no statistical association between tuberculin sensitivity and the various stages of pneumoconiosis; this conclusion was later confirmed by Professor A L Cochrane and others.-P D'ARCY HART, National Institute for Medical Research, London. (Formerly Director, MRC Tuberculosis Research Unit.) 
the aspects of medical practice which differentiate sickness from disease, health from illness, and happiness from distress.

The reason why these parts of medicine are not seen by young doctors as much as they should be is not because of who teaches but because too much teaching takes place in hospital (where illness factors are naturally most apparent) and too little teaching is made available in the community (where patient determinants in the health/illness equation are by implication more prominent and more easily seen). Behavioural medicine is underlearnt in hospital, not because hospital doctors do not practise it but because they do not consistently make its techniques explicit to their studentsmuch in the way general practitioners have often failed to make explicit the cellular components of the medicine of the community.

\section{WHICH FRAMEWORK?}

The cellular framework for medical practice can and will still help medicine advance. A few problems worth tackling remain but the patients who will benefit from new cellular knowledge will become fewer as the century moves to its end. Given the finite nature of life, the contemporary challenges for doctors as physicians as against biological scientists seem more and more to lie in applying existing knowledge effectively and compassionately, in widening awareness of culture and its implications for health, in better communication, in better counselling, and in health education and preventive medicine. The behavioural framework implies no more than a larger emphasis on patient factors than at present, a wider recognition of the importance of the personal qualities of the doctor in determining good outcomes of care, and an implicit willingness to maintain a sensible perspective on the illness element.

Until a generation ago it is arguable whether medicine would have been better categorised as a cellular or as a behavioural science. Perhaps it was a relatively unimportant distinction as matters then stood. Much of the researches of the day were descriptive and epidemiological and most of the patient care was, in today's terms, both straightforward and unpretentious. Paré's dictum of curing sometimes and comforting always was easily visible as the core content of good medicine.

The changes in knowledge and technical competence of the'sixties and 'seventies have made the distinction between the cellular and the behavioural at the same time obvious and problematic. It would be nonsense to suggest that either can survive alone; but I believe that it is in the interests of most in the profession and most of those we serve that the behavioural philosophy should encompass the cellular rather than the reverse. This is the concept of medicine that more fully describes the realities and defines the needs of modern society in health and illness. As this framework is the one that most doctors do in fact use as they practise medicine, whether in general practice or in hospital, the one change that is needed is that this model should be made more clearly explicit in the teaching philosophy of medical schools. Only in this way will the academic thrust of medicine and its institutions be kept properly relevant, balanced, and thus useful to its public.

\section{Conclusions}

My theme has been research in general practice. Much of the researches in general practice during the past two decades have been, as with more established disciplines in their earlier years, necessarily descriptive and epidemiological. Fry and Hodgkin, Watson and Williams, Morrell and Marsh are among the many whose work is now taken for granted, and it is because of their determination and direction that we have a platform to build on. According to the traditional view of research as an additive and cumulative facility, general practice research should now be contributing to understanding the determinants and distribution of disease and helping in experiments to assess therapies-and there is indeed a role and a need for research of this kind.

Nevertheless, if we return to the three histories I used to set my scene-three of the many which any doctor anywhere could describe -we must recognise that the cellular style of general practice research can be expected to have only a most modest part to play in helping our science forward. Hence my subtitle "Pursuit of knowledge or defence of wisdom?"

In 1971 Feinstein wrote: "until the methods of science are made satisfactory for all the important distinctions of human phenomena, our best approach to many problems in therapy will be to rely on the judgements of thoughtful people who are familiar with the total realities of human ailments". ${ }^{9}$ In the researches I have presented from general practice I have worked forward from two assumptions. The first is that most general practitioners, and certainly those interested in looking thoughtfully at what they do, practise medicine which is good in the fullest sense of the word. The second is that hidden in the apparent contrasts and contradictions in what they individually do lie fundamental truths about the definition of that goodness of medical practice which we all strive to seek for as doctors and teachers.

TS Eliot wrote these lines in 1934:

Where is the life we have lost in living?

Where is the wisdom we have lost in knowledge?

Where is the knowledge we have lost in information?

I will conclude by returning to Thomas Kuhn. He argues that the time to rethink the appropriateness of a framework is when it becomes progressively less able to answer the questions asked of it. I believe this is now happening with the cellular theory of medicine and its practice. Personally I see the behavioural theory as better; better because it not only incorporates the now established view but emphasises some of Feinstein's important distinctions of human phenomena and seems to give more scope for future developmentin research, in education, and in clinical practice. I accept Kuhn's further statement that the establishment of the superiority of one model over another may well not be capable of proof and may more appropriately be an issue for scholarship rather than research. Until recently, universities sponsored such scholarship freely and their faculties and their departments used each other in the long term interests of the society which the universities serve. The present climate of higher education, and indeed of health service planning, has swung dangerously towards the pragmatic and away from the philosophical. Let us hope that the balance does not go too far from our control. If the researches of general practice can help preserve the essential relationship between information, knowledge, and wisdom in medicine in its broadest sense, the academic role of the discipline of general practice will be justified.

\section{References}

1 Howie JGR, Richardson IM, Durno D, Gill GM. Respiratory illness and antibiotic use in general

practice. $\mathcal{R}$ Coll Gen Pract 1971;21:657-63.
2 Howie JGR. A new look at respiratory illness in general practice. I R Coll Gen Pract 1973;23:895-

3 Anonymous. Number of prescriptions by therapeutic groups and by selected subgroups. Table 4.19. In: OHE compendium of health statistics. 4th edn. London: HMSO, 1981 .
.

4 Howie JGR. Further observations on diagnosis and management of general practice respiratory illness using simulated patient consultations. $\mathrm{Br}$ Med $\mathcal{F}$ 1974;ii:540-3.

5 Howie JGR. Clinical judgement and antibiotic use in general practice. Br Med F 1976;ii:1061-4. 6 Howie JGR, Bigg AR. Family trends in psychotropic and antibiotic prescribing in general practice. BrMed f 1980;280:836-8.

Bain DJG, Sales CM. Referring children to an ENT department and prescribing psychotropic drugs to their mothers. Br Med $\mathcal{F} 1981 ; 283: 585$

Kuhn TS. The structure of scientific revolutions 2 nd edn. Chicago, University of Chicago Press, pp5,

9 Feinstein AR. The need for humanised science in evaluating medication. Lancet 1972;ii:421.

\section{Answer to Minerva riddle}

According to art historian Panofsky, van Veen's painting alludes to syphilis.' This only became apparent from a study of Luco Giordano's “Allegory of Syphilis" painted in 1664. Giordano's painting contains the same youth and classical figures but his style is high baroque and there is an additional figure, thought to be the shepherd boy Syphilus, who dominates Fracastorius's (1530) poem, and gives his name to the disease.

' Panofsky E. Homage to Fracastoro in a Germano-Flemish composition of about 1590 Netherland Year Book for the History of Art 1961;12:1-38. 